\title{
CONCISE
}

PUBLICATIONS

\section{Detection of the Carrier State in Combined Immunodeficiency Disease Associated with Adenosine Deaminase Deficiency}

\author{
C. Ronald Scott, Shi-Han Chen, and Eloise R. Giblett \\ From the Department of Pediatrics, University of Washington School of \\ Medicine, and the King County Central Blood Bank, Inc., \\ Seattle, Washington 98195
}

\begin{abstract}
A в S T R A C T A large pedigree containing a child with severe combined immunodeficiency disease (CID) associated with adenosine deaminase (ADA) deficiency was investigated to ascertain if heterozygotes could be detected by measuring red cell ADA activity. 9 of 17 individuals in three generations who were at risk for being heterozygous had decreased red cell ADA activity. This genetic information establishes one form of CID as an autosomal recessive disorder. The identified heterozygote population had a mean ADA value of $19.2 \mathrm{U} / \mathrm{g}$ hemoglobin ( 0.95 confidence interval; 14.0 to $24.4 \mathrm{U} / \mathrm{g}$ hemoglobin), which was approximately onehalf the mean, $36.1 \mathrm{U} / \mathrm{g}$ hemoglobin, of a randomly selected control population ( 0.95 confidence interval; 22.5-58.1 U/g hemoglobin). Statistical comparisons of the heterozygotes to the normal population indicates that within a high-risk family heterozygotes may be identified with $90 \%$ confidence.
\end{abstract}

\section{INTRODUCTION}

Severe combined immunodeficiency disease $(\text { CID })^{1}$ is a serious inherited disorder often predisposing to death during early childhood. The condition is characterized by dysfunction of both $\mathrm{B}$ and $\mathrm{T}$ lymphocytes with impaired cellular immunity and decreased production of

Received for publication 11 July 1973 and in revised form 4 Jamuary 1974.

${ }^{1}$ Abbreviations used in this paper: ADA, adenosine deaminase; CGD, chronic granulomatous disease; CID, combined immunodeficiency disease. immunoglobulins. Since CID may be inherited as either an autosomal recessive or X-linked condition, it certainly represents two or more different biochemical defects. The probable cause of one of these disorders was recently reported by Giblett, Anderson, Cohen, Pollara, and Meuwissen (1). They found that adenosine deaminase (ADA) activity was absent from red blood cell hemolysates of two affected patients and was decreased in the parents. Subsequently, at least 12 additional children have been identified who have had ADA deficiency associated with CID (2). This high degree of concurrence implicates ADA deficiency as the first identifiable biochemical cause of an immunodeficient syndrome.

We have recently seen an infant with rapidly fatal CID and ADA deficiency who had a large number of family members (3). In this family the level of ADA activity in red blood cells was investigated to determine if the heterozygous individuals could be distinguished from normal persons.

\section{METHODS}

Samples were collected from 35 healthy men and 32 healthy women varying in age from 19 to 62 yr. 20 family members of the proband served as the study group.

$10 \mathrm{ml}$ of blood was collected by venipuncture and mixed with $2 \mathrm{ml}$ of acid citrate dextrose solution. The red cell hemolysates were prepared by washing the red cells three times with cold saline. To approximately $1 \mathrm{ml}$ of washed packed red cells, we added $1 \mathrm{ml}$ of distilled water and 0.5 $\mathrm{ml}$ of toluene. The mixture was vigorously mixed with a Vortex mixer (Scientific Industries, Inc., Queens Village, 
N. Y.) for $30 \mathrm{~s}$ and centrifuged for $20 \mathrm{~min}$ at $17,000 \mathrm{~g}$. The red cell hemolysate was removed from the bottom of the centrifuge tube with a Pasteur pipette and the upper red cell stromal layer was discarded. The clear, red hemolysate was used for the enzyme assay.

ADA activity in red cell lysates was determined by a modification of the method described by Hopkinson, Cook, and Harris (4), by measuring the rate of absorbance change at $293 \mathrm{~nm}$. The reaction mixture contained $0.06 \mathrm{M}$ phosphate buffer, $\mathrm{pH} 7.5,0.15 \mathrm{mM}$ adenosine, and approximately $0.1 \mathrm{U} / \mathrm{ml}$ of xanthine oxidase (Sigma Chemical Co., Inc., St. Louis, Mo.). The reaction was initiated by adding $10 \mu \mathrm{l}$ of the hemolysates to $2 \mathrm{ml}$ of reaction mixture at $25^{\circ} \mathrm{C}$. An increase of the optical density at $293 \mathrm{~nm}$ was recorded against a blank (without adenosine) for 15 min with a Gilford $2400 \mathrm{~S}$ spectrophotometer (Gilford Instrument Laboratories, Inc., Oberlin, Ohio) and the full range of the recorder was adjusted to 0.2 absorbence units. Enzyme activity was linear for at least $40 \mathrm{~min}$. One unit of enzyme activity was defined as the conversion of $1 \mu \mathrm{mol}$ of substrate/h. Specific activity was expressed as units per gram of hemoglobin. ${ }^{2}$ Hemoglobin was determined by the cyanemethemoglobin method (5).

\section{RESULTS}

The mean activity of red cell ADA from the 32 women was $35.9 \mathrm{U} / \mathrm{g}$ hemoglobin with a range of $21.1-58.2 \mathrm{U} / \mathrm{g}$ hemoglobin. The mean activity of red cell ADA from the 35 men was $36.4 \mathrm{U} / \mathrm{g}$ hemoglobin with a range of 21.0 to $57.2 \mathrm{U} / \mathrm{g}$ hemoglobin. Neither group showed a significant correlation between age and red cell ADA activity. Since there was no statistical difference between the variances and means of the two populations $(P>0.20)$, the two groups were combined. A logarithmic transformation of all numerical values was performed because of a moderately skewed distribution of values towards higher ADA values. The logarithmic transformation achieved a more normal distribution for statistical calculations. The mean value of the combined group was 36.1 with a $0.95 \%$ confidence interval ( $\pm 2 \mathrm{SD}$ ) from $22.5 \mathrm{U} / \mathrm{g}$ hemoglobin to $58.1 \mathrm{U} / \mathrm{g}$ hemoglobin.

When the red cell ADA values from the normal population were used to ascertain the gene status of individuals within the pedigree (Fig. 1), two populations were readily distinguished; those with ADA activity close to the mean of the normal population and those with ADA activity greater than two SDs below the mean. The mother and father of the affected child had values 2.3 and $3.8 \mathrm{SDs}$, respectively, below the mean of the control population $(P<0.01)$. If the parents' values are representative of heterozygote activity, nine additional individuals in the pedigree can be identified as heterozygotes. This assumed heterozygote population had a mean ADA activity of $19.2 \pm 2.6 \mathrm{U} / \mathrm{g}$ hemoglobin, corresponding to approximately one-half of normal control values.

The starch gel electrophoretic pattern of all family

${ }^{2}$ To convert to international units, divide by 60 and units will be expressed as $\mu$ moles of substrate converted per minute per gram hemoglobin. members from this portion of the pedigree contained the three isozymes typical of the ADA 1 phenotype.

\section{DISCUSSION}

The detection of gene carriers for serious genetic disorders is important for understanding the mode of transmission of the defective allele and for adequate genetic counseling. When the fundamental protein defect is unknown, heterozygote detection is difficult and may only be achieved by the chance finding of an altered metabolite or protein which will serve as a gene marker. For autosomal recessive conditions, heterozygotes usually have normal physiological functions because the decreased gene dosage effect is rarely rate limiting. Once a primary biochemical defect is known, direct measurement of the responsible protein has proven to be the most reliable discriminator for the presence of an abnormal allele.

Many of the immunodeficiency diseases have been recognized as having a genetic etiology but only in the $\mathrm{X}$-linked form of chronic granulomatous disease (CGD) have heterozygotes been recognized. The identification of heterozygotes in CGD in three generations of female carriers clearly established one form of CGD as being $\mathrm{X}$-linked $(7,8)$. This was accomplished by using the reduction of nitroblue tetrazolium dye by leukocytes as a gene marker for the leukocyte bactericidal defect. The precise biochemical defect is still unknown.

The results of this study indicate that in CID associated with ADA deficiency, heterozygotes may be detected by measuring ADA activity in red cell hemolysates. The identification of heterozygotes within a threegeneration pedigree establishes ADA deficiency as an

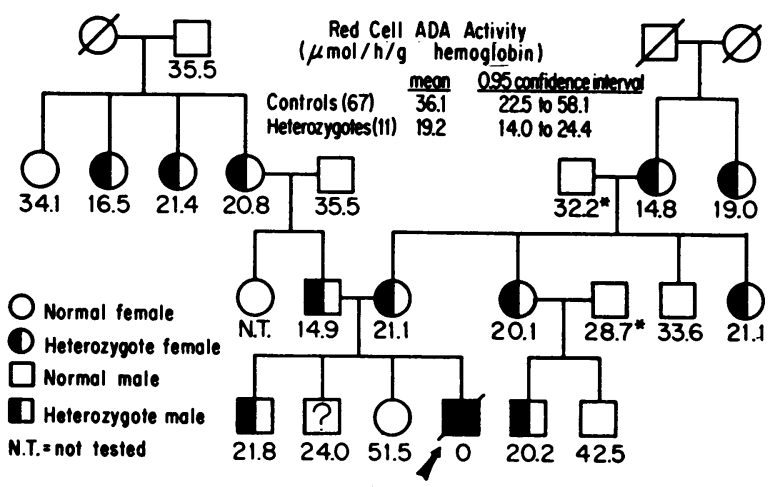

FIGURE 1 In this abbreviated pedigree decreased ADA activity is inherited as an autosomal Mendelian trait. Below each person in the pedigree is his red cell ADA activity expressed in $\mu \mathrm{mol} / \mathrm{h} / \mathrm{g}$ hemoglobin. Family records for more than six generations do not suggest consanguinity. The asterisk indicates a blood sample obtained through the postal service and assayed $48 \mathrm{~h}$ or longer after venipuncture. Under such circumstances the red cell ADA activity is significantly less than it would be if measured fresh. 
autosomal recessive condition. The data from this family indicate that within a family which has been ascertained through a child with ADA deficiency and CID, the probability of correctly identifying a carrier by measuring ADA in red cell hemolysates is approximately 0.90 . The 0.95 confidence interval for the presumed heterozygote hemolysates was $14.0-24.4 \mathrm{U} / \mathrm{g}$ hemoglobin. The normal population had a 0.95 confidence interval of $22.5-58.0 \mathrm{U} / \mathrm{g}$ hemoglobin. The range between 22.5 and $24.4 \mathrm{U} / \mathrm{g}$ hemoglobin represented an area of statistical overlap between the heterozygote group and the normal population. Approximately $10 \%$ of heterozygotes should fall within this indeterminate area, from the data from this pedigree. One sibling of the proband had a value of $24.0 \mathrm{U} / \mathrm{g}$ hemoglobin and could not be reliably assigned to either group.

It had previously been proposed that the ADA produced in tissues other than the red cell was under the control of two or more genetic loci $(6,9)$. Recent evidence would suggest that ADA is under control of a single locus and that "tissue-specific ADA" is secondarily formed by modification of "red cell ADA" by tissue conversion factors (10-12). This implies that a child deficient of ADA in red cells will be similarly deficient of ADA in all tissues. Support for this has been noted by the absence of both the red cell and tissue forms of ADA in cultured skin fibroblasts from a patient with ADA deficiency (13).

It is likely that genetic heterogenity will exist for ADA deficiency. Such heterogeneity will allow a wide clinical spectrum of immunodeficiency depending upon the residual activity, stability, and kinetic properties of the mutant ADA enzyme. One child has already been identified by electrophoresis with red cell ADA deficiency who has no overt clinical evidence of immune deficiency (14). This child is a native of the South African Kalahari region. Although his lymphocyte count and immunoglobin levels were in the normal range, his skin reaction to purified protein derivative was very weak and there was not reaction to Candida or streptokinase/streptodornase. These latter findings did suggest the possibility of some impairment in cellular immunity. Jenkins has suggested this child may have an unstable form of ADA that does not have a normal half-life in the anucleated red cell (14).

The exact mechanism by which ADA deficiency causes CID remains unexplained. Green and Chan postulated that in ADA deficiency, adenosine may accumulate and inhibit pyrimidine biosynthesis (15). The expansion of a lymphocyte clone in response to an antigenic stimulus may be prevented by pyrimidine starvation.

ADA deficiency has now been recognized as a cause for one type of CID. By the measurement of ADA activity in red cells of family members at risk for carrying a silent allele for ADA, the heterozygotes could be identified with a reliability of $90 \%$. This information will be of value in genetic counseling and programs concerned with the treatment and prevention of CID through the use of prenatal diagnosis.

\section{ACKNOWLEDGMENTS}

This work was supported by grants from The National Foundation, The National Institutes of Health (GMI15253, AM-09745) and the Maternal and Child Health Service (proj. 913).

\section{REFERENCES}

1. Giblett, E. R., J. E. Anderson, F. Cohen, B. Pollara, and H. J. Meuwissen. 1972. Adenosine-deaminase deficiency in two patients with severely impaired cellular immunity. Lancet. 2: 1067.

2. Combined immunological disease-a molecular defect? 1973. Birth Defects Institute Symposium IV. New York State Health Department, Albany, N. Y. In press.

3. Ochs, H. D., J. E. Yount, E. R. Giblett, S.-H. Chen, C. R. Scott, and R. J. Wedgwood. 1973. Adenosinedeaminase deficiency and severe combined immunodeficiency syndrome. Lancet. $1: 1393$.

4. Hopkinson, D. A., P. J. L. Cook, and H. Harris. 1969. Further data on the adenosine deaminase (ADA) polymorphism and a report of a new phenotype. Ann. Hum. Genet. 32: 361.

5. Beutler, E. 1971. Red cell metabolism: a manual of biochemical methods. Grune \& Stratton Inc., New York. 13.

6. Spencer, N., D. A. Hopkinson, and H. Harris. 1968. Adenosine deaminase polymorphism in man. Ann. Hum. Genet. $32: 9$.

7. Windhorst, D. B., B. Holmes, and R. A. Good. 1967. A newly defined $x$-linked trait in man with demonstration of the Lyon effect in carrier females. Lancet. 1: 737.

8. Windhorst, D. B., A. R. Page, B. Holmes, P. G. Quie, and R. A. Good. 1968. The pattern of genetic transmission of the leukocyte defect in fatal granulomatous disease of childhood. J. Clin. Invest. 47: 1026.

9. Edwards, Y. H., D. A. Hopkinson, and H. Harris. 1971. Adenosine deaminase isozymes in human tissues. Ann. Hum. Genet. 35 : 207.

10. Akedo, H., H. Nishihara, K. Shinkai, and K. Komatsu. 1970. Adenosine deaminases of two different molecular sizes in human tissues. Biochim. Biophy's. Acta. 212: 189.

11. Nishihara, H., S. Ishikawa, K. Shinkai, and H. Akedo. 1973. Multiple forms of human adenosine deaminase. II. Isolation and properties of a conversion factor from human lung. Biochim. Biophys. Acta. 302: 429.

12. Hirschhorn, R., and N. G. Beratis. 1973. Severe combined immunodeficiency and adenosine-deaminase deficiency. Lancet. 2: 1217.

13. Chen, S-H., and C. R. Scott. 1973. Adenosine deaminase in cultured skin fibroblasts and amniotic fluid cells: potential use for prenatal diagnosis of combined immunodeficiency disease. Am. J. Hum. Genet. 25: 21A.

14. Jenkins, T. 1973. Red-blood-cell adenosine deaminase deficiency in a "healthy" Kung individual. Lancet. 2: 736.

15. Green, H., and T.-S. Chan. 1973. Pyrimidine starvation induced by adenosine in fibroblasts and lymphoid cells : role of adenosine kinase. Science (Wash., D. C.). $182: 836$. 